\title{
Performance of Heuristic Optimization in Coordination of Plug-In Electric Vehicles Charging
}

\author{
Sara Deilami, Amir S. Masoum, Mohammad A.S. Masoum and A. Abu- Siada \\ Department of Electrical and Computer Engineering, Curtin University, WA, Australia \\ Correspondence should be addressed to: Amir S. Masoum; amir.sherkatmasoum@westernpower.com.au
}

Received 1 March 2013; Accepted 1 April 2013; Published 26 June 2013

Academic Editor: Enrique Romero-Cadaval

Copyright (c) 2013 Sara Deilami, Amir S. Masoum, Mohammad A.S. Masoum and A. Abu- Siada. Distributed under Creative Commons CC-BY 3.0

\begin{abstract}
A heuristic load management (H-LMA) algorithm is presented for coordination of Plug-in Electric Vehicles (PEVs) in distribution networks to minimize system losses and regulate bus voltages. The impacts of optimization period $\mathrm{T}$ (varied from 15 minutes to 24 hours) and optimization time interval (varied 15 minutes to one hour) on the performance, accuracy and speed of the H-LMA is investigated through detailed simulations considering enormous scenarios. PEV coordination is performed by considering substation transformer loading while taking PEV owner priorities into consideration. Starting with the highest priority consumers, $\mathrm{H}$ LMA will use time intervals to distribute PEV charging within three designated high, medium and low priority time zones to minimize total system losses over period $\mathrm{T}$ while maintaining network operation criteria such as power generation and bus voltages within their permissible limits. Simulation results generated in MATLAB are presented for a 449 node distribution network populated with PEVs in residential feeders.
\end{abstract}

Index Terms- Heuristic optimization, electric vehicles and load management.

\section{Introduction}

Preliminary studies by Amin et al. (2005), Amin (2008) and Lightner et al. (2010) indicate that Plug-In Electric Vehicles (PEVs) will dominate the market in the near future as pollution-free alternatives to the conventional petroleum- based transportation. However, according to Moses et al. (2010), Masoum et al. (2011) and Moses et al. (2012), uncoordinated PEV charging specially at high penetration levels during the peak load hours may cause undesirable impacts on the power grid such as unpredictable system peaks, unaccepted voltage deviations, significant increases in losses and poor power quality, as well as overloading of the distribution and substation transformers. This has motivated researchers to propose and implement different PEV coordination algorithms.

In general, PEV chargers can be controlled to operate in charge or discharge modes with the energy being transferred from grid to vehicle (V2G) or from vehicle to grid $(G 2 V)$, respectively. One of the first approaches for PEV coordination based deterministic and stochastic dynamic

Cite this Article as: Sara Deilami, Amir S. Masoum, Mohammad A.S. Masoum and A. Abu- Siada (2013), "Performance of Heuristic Optimization in Coordination of Plug-In Electric Vehicles Charging," International Journal of Renewable Energy and Biofuels, Vol. 2013 (2013), Article ID 898203, DOI: $10.5171 / 2013.898203$ 
programing was presented by ClementNyns et al. (2010). Masoum et al. (2011) performed peak load saving with PEV coordination without considering the random nature of PEV arrivals and departures. A relatively fast PEV coordination algorithm suitable for online applications is proposed by Deilami et al (2011). Ashtari et al. (2012) predicted PEV charging profiles and electrical range reliability based on recorded vehicle usage data. Wu et al (2012) designed a minimumcost load scheduling algorithm based on the forecasted electricity price and PEV power demands. In a research study by Khodayar et al. (2012) and Zhao et al. (2012), the PEV coordination problem is performed considering the impact of wind power generation. Wen et al. (2012) and $\mathrm{Ma}$ et al. (2013) have presented decentralized charging control algorithms considering large populations of PEVs. There are also many documents investigating the operation of PEVs in V2G mode to support the grid by performing frequency regulation and/or energy storage including the research performed by Bashash et al. (2012), Han (2010) and Sortomme et al. (2011).

This paper will first present a heuristic load management algorithm (H-LMA) to coordinate PEV charging activities while reducing system losses and regulating bus voltages over a 24 hour period. Then, simulation results will be presented for a 449 node distribution network populated with PEVs in residential feeders. Finally, the impacts of heuristic optimization parameters including optimization period $T$ and optimization time interval $\Delta t$ on the accuracy and speed of H-LMA will be investigated.

\section{Problem Formulation}

PEV charge coordination is a constrained optimization problem that could be solved by using online algorithms (i.e., PEV coordination is performed as soon as vehicles are randomly plugged-in) or offline schemes (i.e., all vehicles are assumed to be plugged-in according to their pre-known/forecasted charging patterns). This paper assumes the charging patterns of all PEVs are known or forecasted and utilizes a heuristic approach to solve the optimization problem.

The optimization problem objective function is formulated based on the minimization of total system power losses:

$\min W_{l o s s}=\sum_{t} P_{t}^{l o s s}, \quad t=\Delta t, 2 \Delta t, 3 \Delta t, \ldots . T$

$$
P_{t}^{\text {loss }}=\sum_{k=1}^{n-1} R_{k, k+1}\left(\left|V_{k+1}-V_{k} \| y_{k, k+1}\right|\right)^{2}
$$

Where $\Delta t$ and $T$ are the optimization time interval and period used for loss minimization. $P_{t}^{l o s s}$ is the system power loss at time $t$ (computed using the Newtonbased power flow), $V_{k}$ is voltage of node $k$ at time $t$, and $n$ is total number of nodes while $R_{k, k+1}$ and $y_{k, k+1}$ are resistance and admittance of line section between nodes $k$ and $k+1$.

PEV coordination constraints are node voltage limits and system demand level at time $t$ :

$$
\begin{aligned}
& V^{\text {min }} \leq V_{k} \leq V^{\text {max }} \text { for } k=1, . ., n . \\
& P_{\text {max demand }, t}=\sum_{k=1}^{n-1} P_{k, t}^{\text {load }} \leq D_{\text {max, }} \text { (3) } \\
& V^{\text {min }}=0.9 p u, \quad V^{\max }=1.1 p u, \quad \text { and } \\
& P_{\text {maxdemand,t }} \text { is the total power } \\
& \text { consumption at time } t, P_{k, t}^{\text {load }} \text { is the power } \\
& \text { consumption of node } k \text { at time } t \text { and } D_{m, t} \text { is } \\
& \text { the maximum demand level at time } t \text { that } \\
& \text { would normally occur without any PEVs. }
\end{aligned}
$$

The load flow and proposed algorithm are coded using MATLAB software package. All parameters and variables are written in complex rectangular form. 


\section{Heuristic Load Management Algorithm (H-LMA)}

A MATLAB based algorithm has been developed to perform PEV scheduling based on H-LMA (Fig. 1). The algorithm will perform loss minimization over the optimization period $T$ using time interval $\Delta t$ based on Eqs. 1-2 while considering the system constraints (Eqs. 3-4). Three charging time zones are defined:

- Red charging zone (18:00h-22:00h) coinciding with most of the on-peak period and is designated for highpriority PEV owners willing to pay higher tariff rates in order to charge their vehicles as soon as possible.

- Blue charging zone (18:00h-01:00h) intended for medium-priority consumers that prefer to charge their vehicles at partially off-peak periods and pay lower tariff rates.

- Green charging zone (18:00h-08:00h) when most PEV charging will probably take place due to the cheapest tariff rates as most low-priority consumers will require their vehicles fully charged for the following day.

The algorithm assumes all PEVs are plugged in at 18:00 (6pm). It begins by first reading the input parameters (e.g., bus and branch impedance data, nodes with PEVs, optimization period $T$, optimization time interval $\Delta t$, designated priority time zones, load profiles for PEV chargers and residential loads as well as system constraints) and performing initialization (e.g., selecting the highest priority group, time zone and PEV).
The main program loop is progressing from high to low PEV priority groups (e.g., red zone to green zone). Within the selected priority group, individual PEVs are temporarily activated to determine system performance at all possible PEV nodes and charging time combinations within that priority charging time zone. From these combinations, the algorithm selects the PEV within the group and the charging start time resulting in the minimum system losses, taking into consideration the charging duration and the current demand level. The physical node location at which PEV charging occurs is an important factor as it impacts the load flow, power losses in the cables and system voltage profile. Therefore, the H-LMA determines the PEV node and charging time that will result in the least system losses (Eq. 2).

If at any time the load flow indicates a constraint violation at any node (Eqs. 3-4), the algorithm will try the next possible charging start time such that the constraints are satisfied. Therefore, it may not be possible for all PEV owners to be accommodated in their preferred charging zones and must be deferred to the next possible hour. Once it has been determined which PEV node in that priority group can begin charging and at what time resulting in minimum system losses, the selected PEV scheduling is permanently assigned and the system load curve updated ready for the next iteration. This process is repeated for all nodes in that priority group before advancing to the next prioritycharging zone (e.g., blue zone subscribers). At the end of this process, the H-LMA arrives at individual schedules assigned to all PEV chargers. The program then exits the main loop and computes the 24 hour load flow to print new system performances (e.g., all node voltage profiles and power losses). 


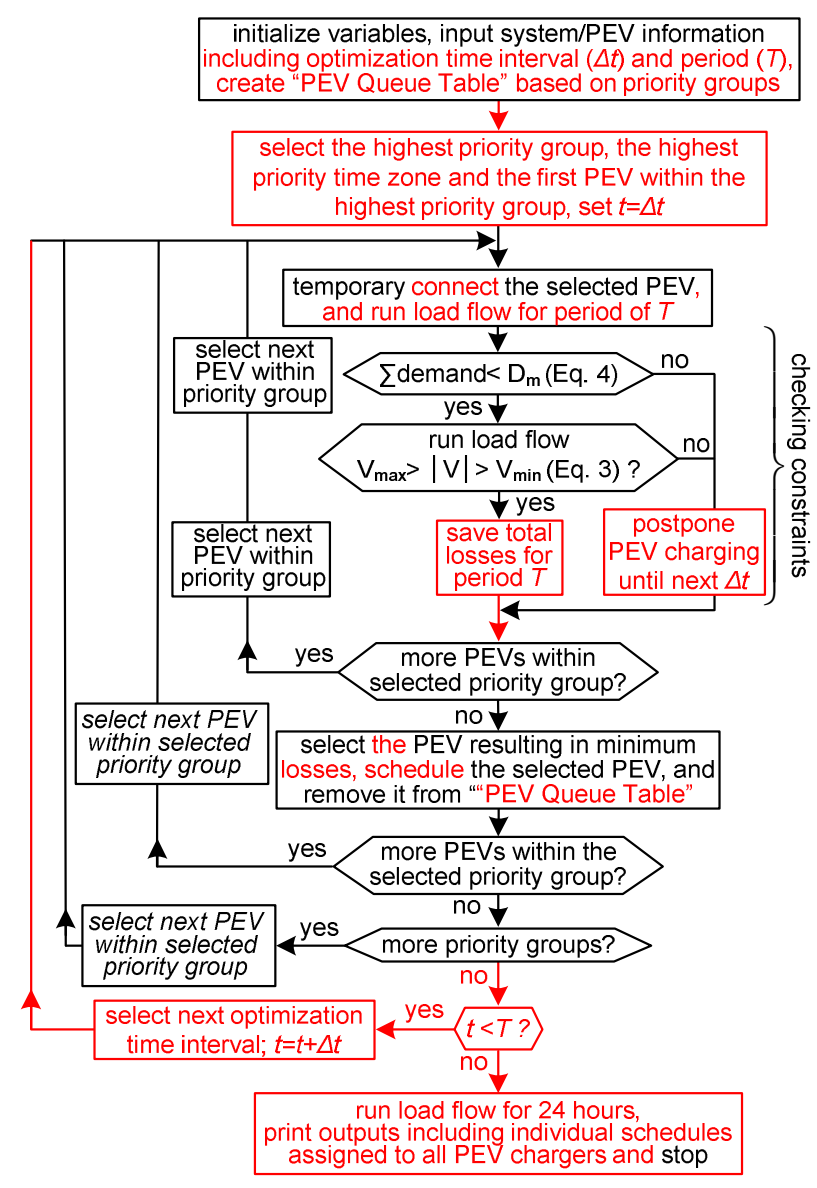

\section{Fig. 1: Proposed H-LMA for Coordination of Pevs to Minimize Total System Losses over Period $T$ Using Optimization Time Interval $\Delta t$ Considering Node Voltage Profiles and Maximum Demand Level}

\section{Smart Grid Test System}

The selected test system is a modification of the IEEE 31 bus $23 \mathrm{kV}$ distribution systems (Deilami et al (2011)) combined with 22 residential 19 nodes LV $415 \mathrm{~V}$ networks populated with PEVs. The resulting 449 node system is supplied from the $\mathrm{HV}$ main bus via a $23 \mathrm{kV} / 415 \mathrm{~V} 100 \mathrm{kVA}$ distribution transformer as shown in Fig. 2. System data are listed in the Appendix.

The peak power consumption of a house is assumed to be on average $2 \mathrm{~kW}$ with a power factor of 0.9. Four PEV penetration levels are selected including 16\% (with nodes "o", "b" and "q" randomly designated with red, blue and green priorities, respectively), 32\% (with nodes "o", "b, r" and " $f, h, q$ " randomly designated with red, blue and green priorities, respectively),
$47 \%$ (with nodes "o", "b, j, r" and "f, g, h, m, q" randomly designated with red, blue and green priorities, respectively) and $63 \%$ (with nodes "o, s", "b, d, j, r" and "f, g, h, k, $\mathrm{m}, \mathrm{q}$ " randomly designated with red, blue and green priorities, respectively).

For this study, a $10 \mathrm{kWh}$ battery capacity per PEV with a depth of discharge (DOD) of $70 \%$ and battery charger efficiency of $88 \%$ is assumed (Deilami et al (2011)) which will require a total of $8 \mathrm{kWh}$ of energy from the grid to charge a single PEV. A standard single-phase $240 \mathrm{~V}$ outlet (Australia) can typically supply a maximum of $2.4 \mathrm{~kW}$. There are also 15A and 20A outlets (singlephase and three-phase) which can supply approximately $4 \mathrm{~kW}$ and $14.4 \mathrm{~kW}$, respectively. In this paper, a fixed charging power of $4 \mathrm{~kW}$ is used. 


\section{Simulation Results and Discussion}

Simulation results for uncoordinated and coordinated (using H-LMA of Fig. 1) PEV charging for the smart grid system of Fig. 2 are presented in Figs. 3-5 and Tables 1 and2.

Table 1: Comparison of Simulation Results for Uncoordinated and Coordinated (H-Lma, =15 Min, T=24 Hours) Pev Charging for the Smart Grid Test System of Fig. 3: Pevs are Assumed to be Randomly Arriving at Each Time Interval. For Comparison, Consumer Priorities are not considered and the Same Gaussian Random Distributions are Used in the Simulations.

\begin{tabular}{|c|c|c|c|c|c|c|c|}
\hline \multirow[t]{2}{*}{ Case Study } & \multirow[t]{2}{*}{$\begin{array}{c}\text { PEV } \\
\text { Penetration } \\
\text { level }\end{array}$} & \multicolumn{3}{|c|}{$\begin{array}{c}\text { CASE A: UNCOORDINATED PEV } \\
\text { CHARGING } \\
\text { (RANDOM CHARGING) }\end{array}$} & \multicolumn{3}{|c|}{$\begin{array}{c}\text { CASE B: COORDINATED PEV } \\
\text { CHARGING } \\
\text { (USING H-LMA OF FIG. 1) }\end{array}$} \\
\hline & & $\begin{array}{c}\Delta \text { loss }^{*} \\
{[\%]} \\
\end{array}$ & $\Delta \mathrm{V}^{* *}[\%]$ & $\begin{array}{c}\mathrm{I}_{\text {MAX }} * * * \\
{[\%]}\end{array}$ & $\begin{array}{c}\Delta \text { loss } \\
{[\%]}\end{array}$ & $\Delta \mathrm{V}[\%]$ & $\mathrm{I}_{\operatorname{MAX}}[\%]$ \\
\hline \multirow{4}{*}{$\begin{array}{l}\text { No PRIORITY, } \\
\text { CHARGING } \\
\text { PERIOD: } \\
\text { 6PM-10PM }\end{array}$} & $16 \%$ & 2.3553 & 7.8499 & 0.5546 & 2.3332 & 7.646 & 0.47243 \\
\hline & $32 \%$ & 2.5312 & 9.2298 & 0.64324 & 2.4048 & 7.646 & 0.47243 \\
\hline & $47 \%$ & 2.9263 & 15.8182 & 0.77095 & 2.5849 & 10 & 0.51682 \\
\hline & $63 \%$ & 3.089 & 17.1467 & 0.88626 & 2.5963 & 9.9996 & 0.54002 \\
\hline \multirow{4}{*}{$\begin{array}{l}\text { No PRIORITY, } \\
\text { CHARGING } \\
\text { PERIOD: } \\
\text { 6PM-1AM } \\
\end{array}$} & $16 \%$ & 2.3401 & 7.6984 & 0.52591 & 2.3149 & 7.646 & 0.44071 \\
\hline & $32 \%$ & 2.4712 & 8.5243 & 0.57259 & 2.4172 & 7.7832 & 0.45499 \\
\hline & $47 \%$ & 2.7659 & 13.9102 & 0.64256 & 2.5737 & 9.7039 & 0.45872 \\
\hline & $63 \%$ & 2.8706 & 14.7455 & 0.68842 & 2.6217 & 9.7946 & 0.49038 \\
\hline \multirow{4}{*}{$\begin{array}{l}\text { No PRIORITY, } \\
\text { CHARGING } \\
\text { PERIOD: } \\
\text { 6PM-8AM }\end{array}$} & $16 \%$ & 2.3141 & 7.7242 & 0.47831 & 2.2939 & 7.646 & 0.44071 \\
\hline & $32 \%$ & 2.3818 & 8.3553 & 0.52900 & 2.3411 & 7.646 & 0.44071 \\
\hline & $47 \%$ & 2.6188 & 13.6146 & 0.60348 & 2.4936 & 8.7893 & 0.44071 \\
\hline & $63 \%$ & 2.6184 & 14.3304 & 0.58385 & 2.4921 & 9.1211 & 0.44071 \\
\hline
\end{tabular}

${ }^{*}$ ) Ratio of system losses over 24 hours compared to total power consumption over 24 hours.

**) Voltage devataion at the worst bus.

***) Maximum of all distribution transformer load current.

\section{A. Case A: Random PEV Charging}

Simulation results of Fig. 3 and Table 1 highlight the detrimental impacts of uncoordinated PEV charging at four penetration levels. As expected and well documented, random charging, especially during the peak residential load hours (18:00-22:00), results in unpredictable power consumption peaks (Fig. 3(a), at
19:45 for $63 \%$ PEV penetration), unaccepted voltage deviations (Fig. 3(b), at node $15-\mathrm{i}$ for $63 \%$ and $47 \%$ PEV penetrations at 19:45) and significant increase in losses (Fig. 3(c), 110kW, 85kW, $47 \mathrm{~kW}$ and $30 \mathrm{~kW}$ for PEV penetration levels of $63 \%, 47 \%, 32 \%$ and $16 \%$, respectively, at 19:45). Detailed simulation results for this case study are presented in Table 1 (columns 3-5). 


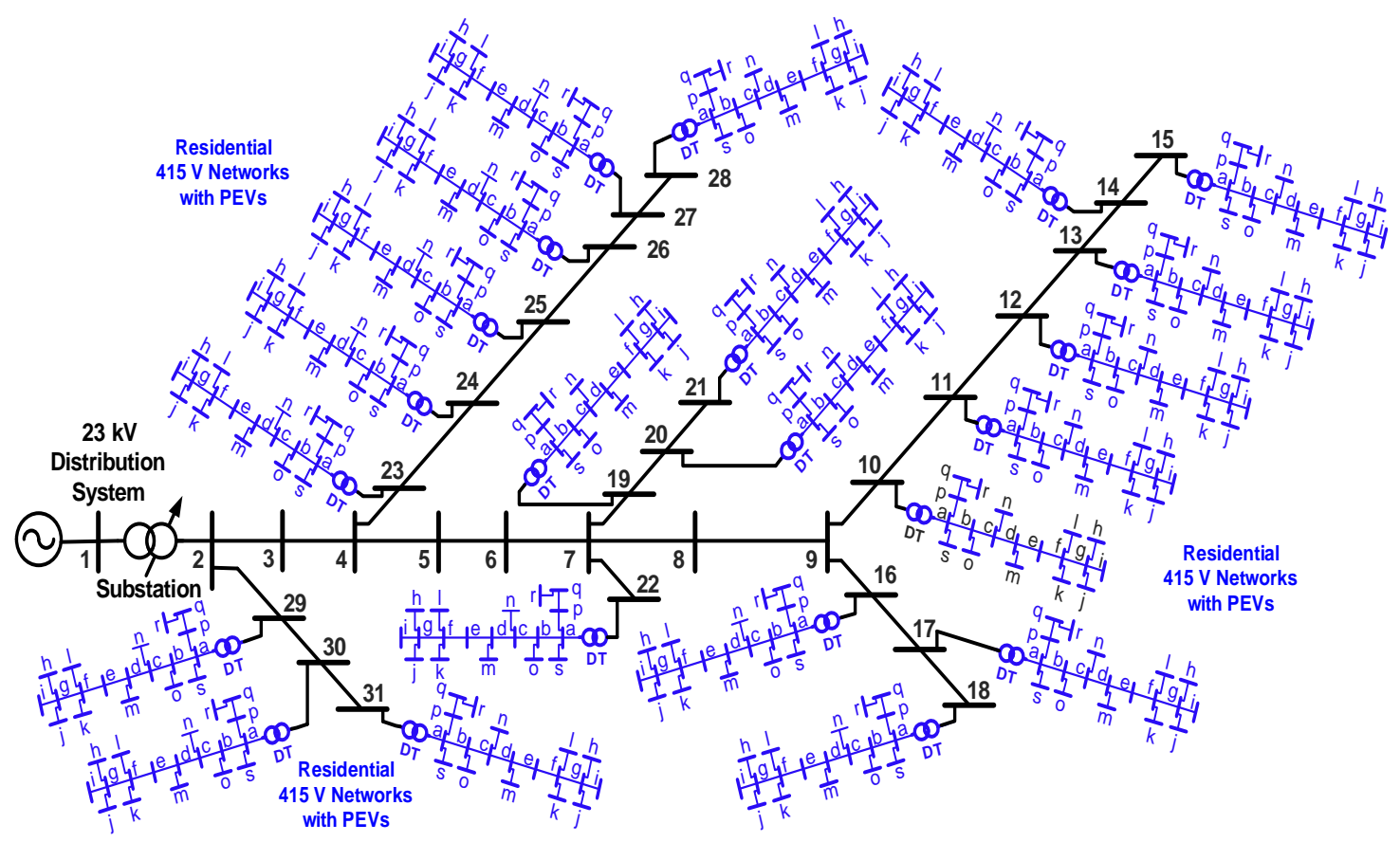

Fig. 2: The 449 Node Smart Grid Test System Consisting of the IEEE 31 Node 23 Kv System with Several 415 V Residential Feeders. Each Low Voltage Residential Network Has 19 Nodes Representing Customer Households Populated with Pevs Randomly Arriving within 24 Hours.

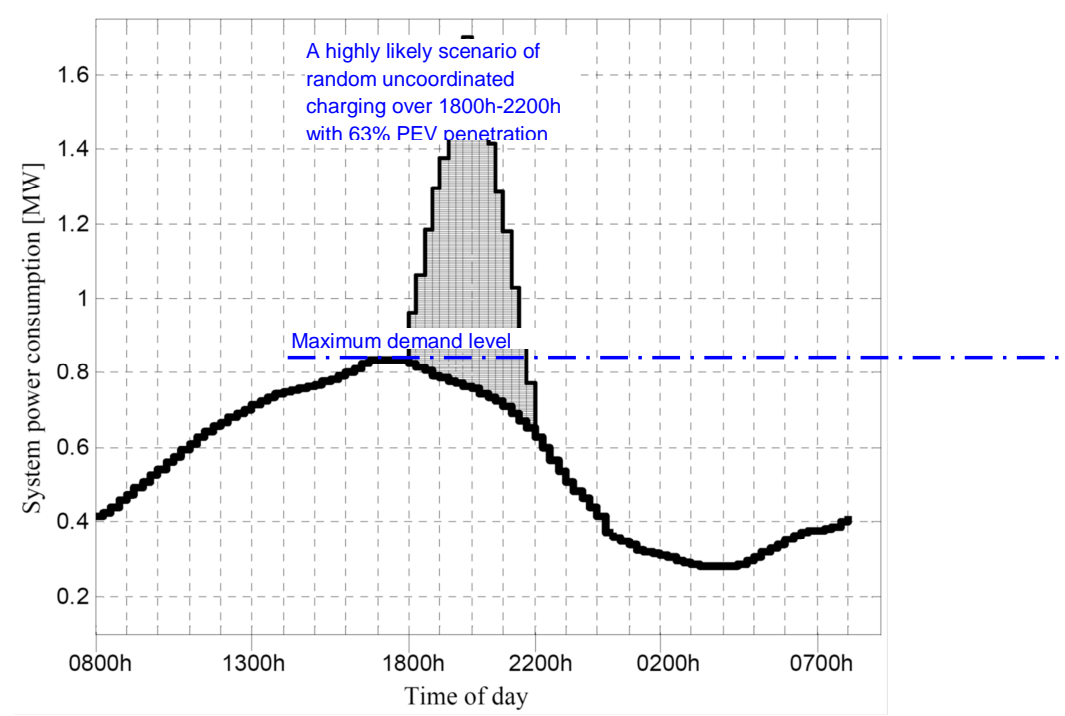

(a) 


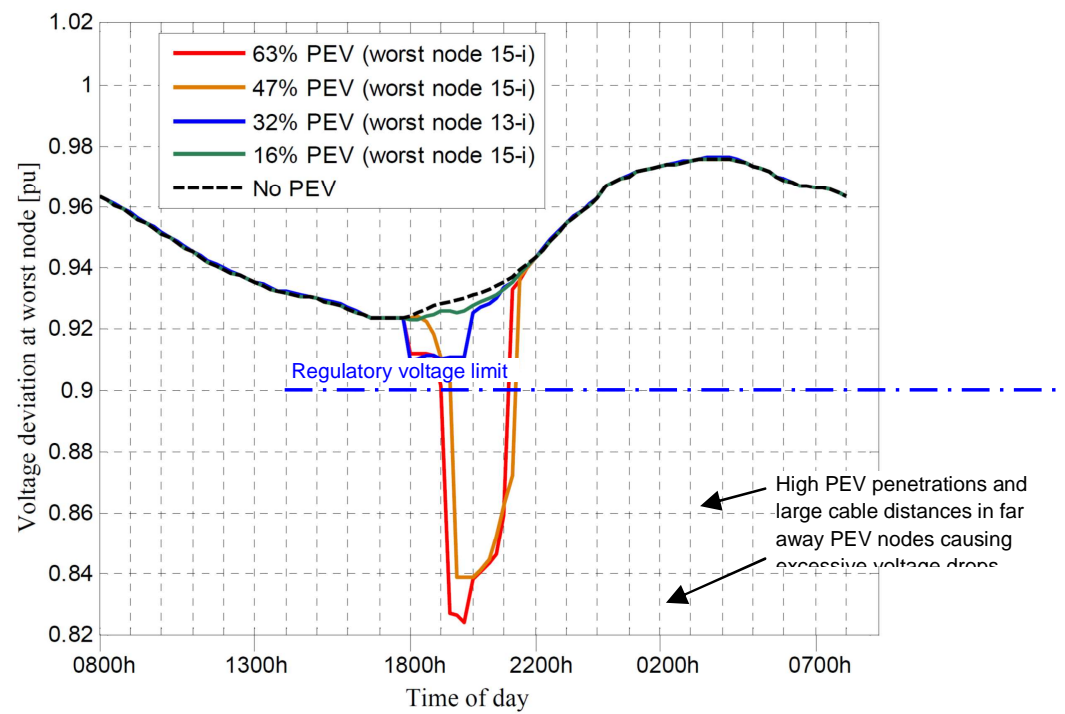

(b)

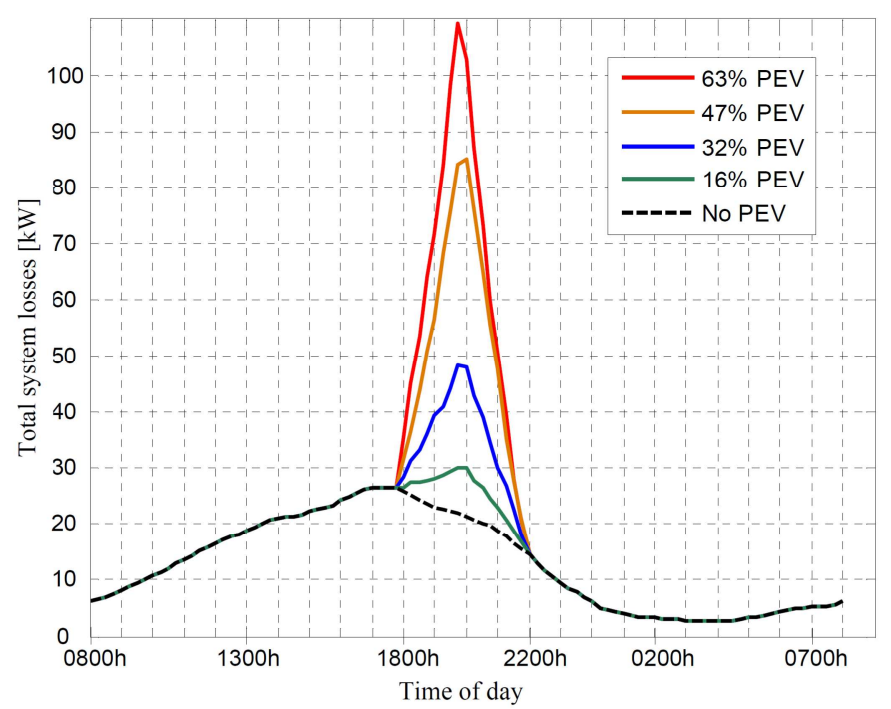

(c)

Fig. 3: Simulation Results ( $\Delta t=15$ Min, $T=24$ Hours) for Random Uncoordinated PEV Charging Across the Red Zone (Case A1: 18:00h-22:00h); (A) System Power Consumption for 63\% PEV Penetration, (B) Voltage Profile (For the Worst Affected Nodes), (C) Total System Power Losses. 


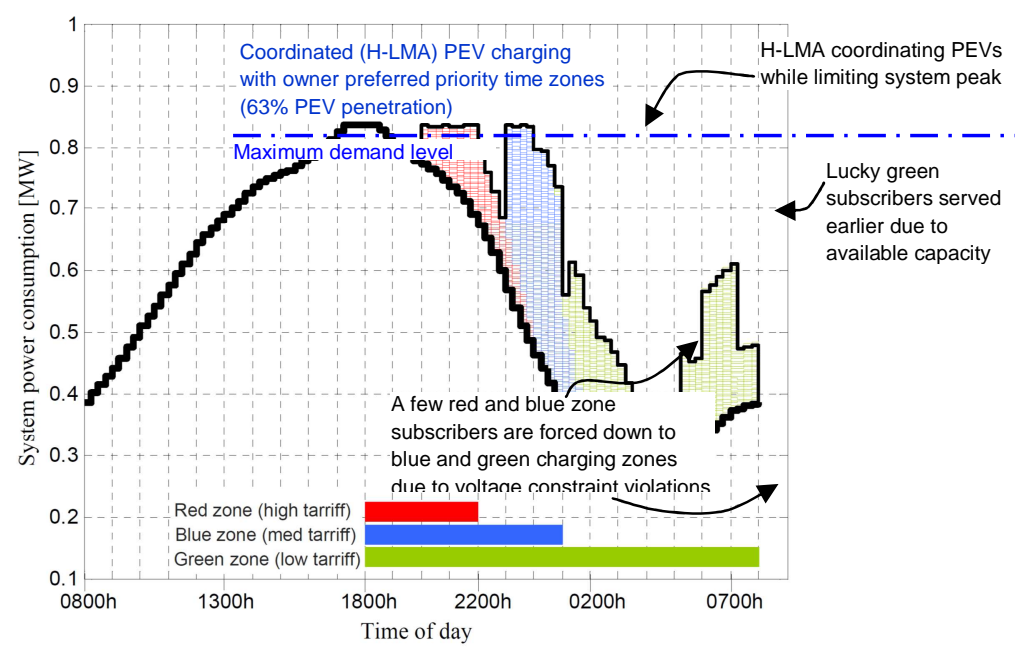

(a)

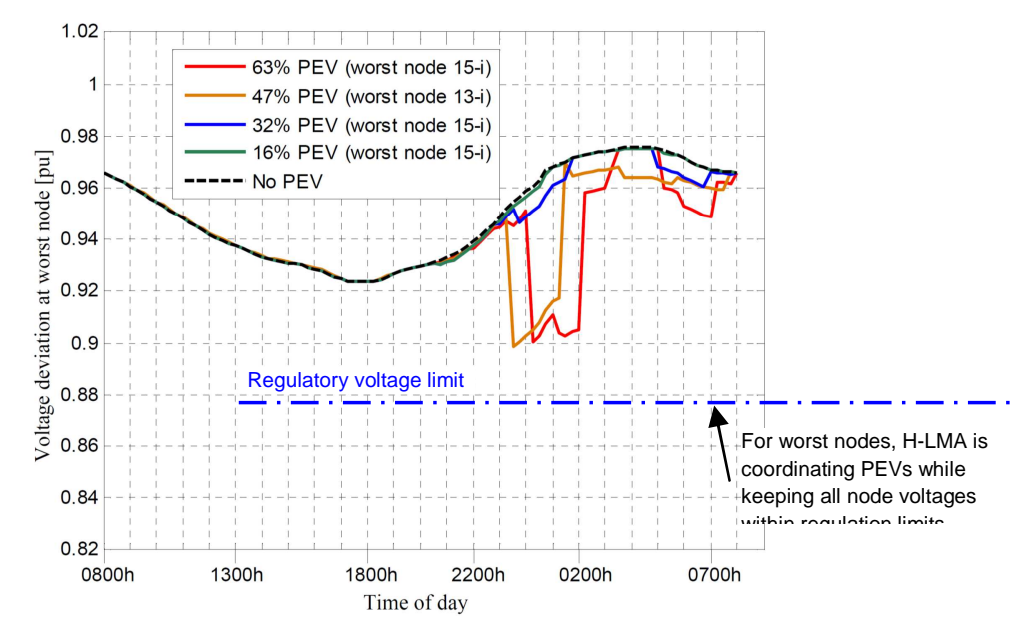

(b)

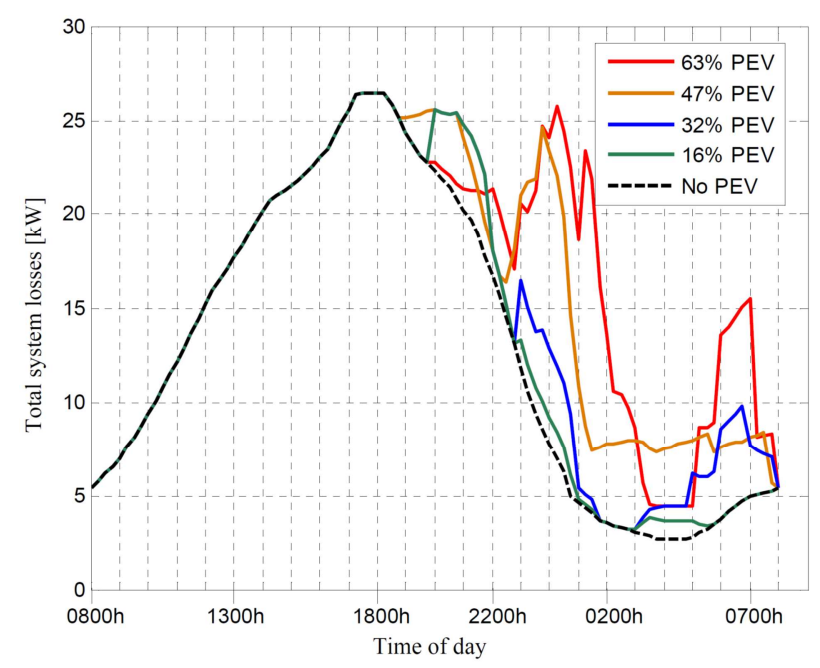

(c)

Fig. 4: Simulation Results ( $\Delta t=15$ Min, $T=24$ Hours) for Coordinated PEV Charging Using the Proposed H-LMA of Fig. 1; (A) System Power Consumption for 63\% PEV Penetration,

(B) Voltage Profile (For the Worst Affected Nodes), (C) Total System Power Losses. 


\section{B. Case B: H-LMA Coordinated PEV Charging}

Coordinated PEV charging is performed with (Fig. 4-5) and without (Table 1) PEV owner preferred time zone priorities. Compared to Case A, a significant improvement in smart grid performance is achieved. Most notably, the system demand peak has been reduced (Figs. 3(a) and 4(a)) which is more favorable from a standpoint of generation dispatch and preventing overloads.

Comparison of results also indicate the significant impacts of coordinated (H-LMA) PEV charging on voltage profile where the unacceptable voltage deviations of about $17 \%$ (Fig. 3(b)) at the worst bus for uncoordinated PEV charging is compensated to less than 10\% (Fig. 4(b)) which is within the regulation limits. However, there is a trade off in that a few PEV subscribers who designated a preferred priority charging time zone were not accommodated in their requested charging zone (Fig. 4(a)) because the system reached a point where PEV loading caused voltage regulation to be violated. $\mathrm{H}$ LMA handled these cases by attempting to schedule the PEV owners causing the violations to a charging time where the system is not under strain, thereby satisfying constraints.

The improvements in system efficiency with H-LMA coordination strategy are also evident in Table 1. Energy losses for the high penetration (63\%) with H-LMA are limited to $2.59 \%$ of system consumption versus the worst uncoordinated charging scenario with losses of $3.09 \%$.

Furthermore, peak power losses are limited to less than a third of the worst case random uncoordinated charging (Fig. 4(c)). The H-LMA charging also has positive impacts on peak transformer load currents.
For many of the uncoordinated random charging scenarios (Table 1), distribution transformers are experiencing load currents of up to $0.88 \mathrm{pu}$, while with $\mathrm{H}$ LMA coordination, transformer currents are reduced to levels of approximately 0.54 pu (Table 1).

\section{Case C: Impacts of $\triangle t$ and T on PEV Coordination}

Detailed simulations are presented and compared in Table 2 to highlight impacts of $\Delta t$ and $T$ (Eq. 1 ) on the performance of $\mathrm{H}$ LMA. In general, the speed and accuracy of the PEV coordination algorithms will depend on the selection of optimization time interval $(\Delta t)$ and period $(T)$.

The accuracy can be improved by using shorter time intervals (e.g., checking the status of PEVs and network as quickly as possible based on online information and measurements available through smart meters) and performing loss minimization over a long period (e.g., 24 hours). However, the drawback is the computing time will dramatically increase, especially in realistic large smart grids with many nodes and high penetration levels of PEVs. Therefore, a compromise should be made between the solution accuracy and computation time considering system size and the anticipated PEV penetration level.

Based on the results of Table 2, the practical options may be to use moderate time intervals with large optimization periods for offline PEV coordination (e.g., $\Delta t=60 \mathrm{~min}$ and $T=24$ hours for applications where all vehicles are plugged-in or their charging patterns are known/forecasted before the start of optimization) and select small values for online PEV coordination (e.g., $\Delta t=T=15$ min to start charging batteries as soon as vehicles are randomly plugged-in). 
Table 2: Impact of Coordinated (H-Lma) Pev Charging with Diffident Optimization Time Interval $\Delta$ T And Period T (Eq. 1) Values on the Power Quality and Performance of Smart Grids Test System of Fig. 2.

\begin{tabular}{|c|c|c|c|c|c|}
\hline \multirow{2}{*}{$\begin{array}{l}\text { Penetration } \\
\text { of PEV [\%] }\end{array}$} & \multicolumn{5}{|c|}{ COORDINATED PEV CHARGING (H-LMA) BASED ON LOSS MINIMIZATION (EQS. 1-4) } \\
\hline & $\Delta \operatorname{loss}[\%]$ & $\Delta \mathrm{V}[\%]$ & $\mathrm{I}_{\mathrm{MAX}}[\%]$ & $\mathrm{E}_{\text {loss }}{ }^{*}[\mathrm{kWh}]$ & Computing time $^{* *}$ \\
\hline \multicolumn{6}{|c|}{ CASE B: $\Delta t=15$ MIN, LOSS MINIMIZATION OVER $T=24$ HOURS } \\
\hline 16 & 2.336 & 7.646 & 0.443 & 326.4 & 15.7 mins \\
\hline 32 & 2.373 & 7.646 & 0.444 & 344.1 & $2.02 \mathrm{hrs}$ \\
\hline 47 & 2.530 & 9.999 & 0.444 & 380.2 & 5.53 hrs \\
\hline 63 & 2.551 & 9.999 & 0.4801 & 396.9 & $6.29 \mathrm{hrs}$ \\
\hline \multicolumn{6}{|c|}{ CASE C: $\Delta t=60$ MIN, LOSS MINIMIZATION OVER $T=24$ HOURS } \\
\hline 16 & 2.319 & 7.646 & 0.440 & 321.2 & 5.2 mins \\
\hline 32 & 2.372 & 7.646 & 0.455 & 340.9 & 26.9 mins \\
\hline 47 & 2.520 & 9.996 & 0.441 & 375.6 & $1.14 \mathrm{hrs}$ \\
\hline 63 & 2.530 & 9.562 & 0.450 & 390.4 & $1.55 \mathrm{hrs}$ \\
\hline \multicolumn{6}{|c|}{ CASE D: $\Delta t=15$ MIN, LOSS MINIMIZATION OVER $T=\Delta t=15$ MIN } \\
\hline 16 & 2.338 & 7.646 & 0.442 & 326.7 & 2.33 mins \\
\hline 32 & 2.375 & 7.646 & 0.462 & 344.4 & $17.67 \mathrm{mins}$ \\
\hline 47 & 2.517 & 9.999 & 0.462 & 378.3 & 48.4 mins \\
\hline 63 & 2.529 & 9.999 & 0.458 & 399.4 & 56.9 mins \\
\hline
\end{tabular}

*) Total energy consumption over $T$.

**) Intel Core 2 Quad 3.0 GHz processor, 8 GB RAM, using MatLab ver. 7

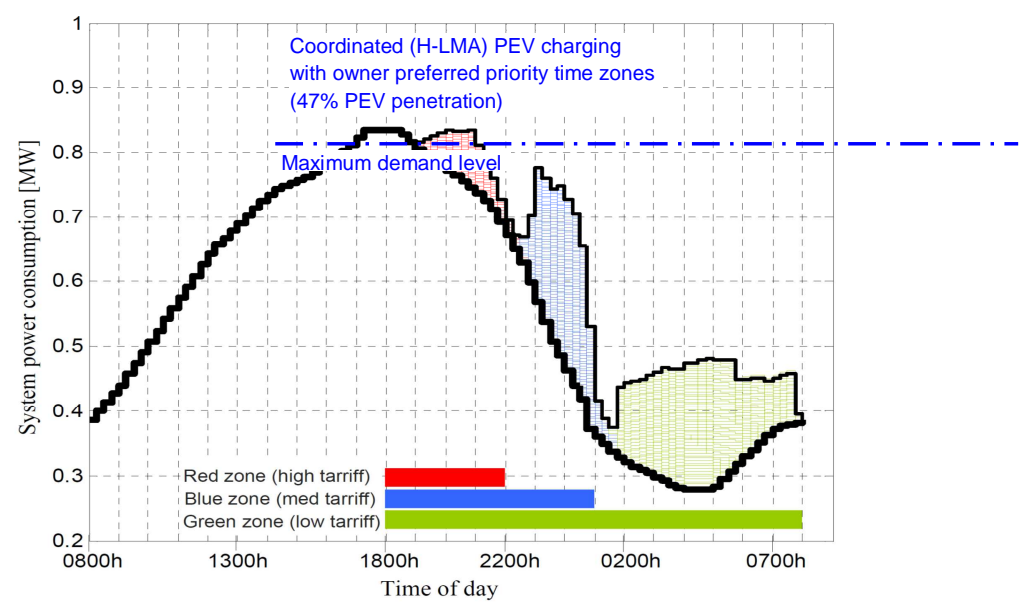

(a) 


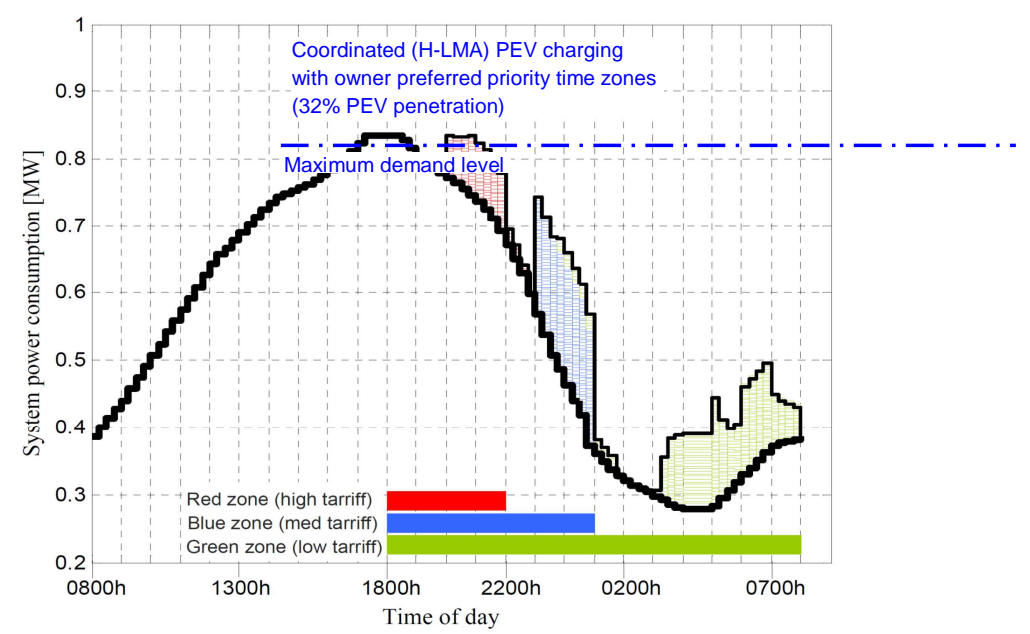

(b)

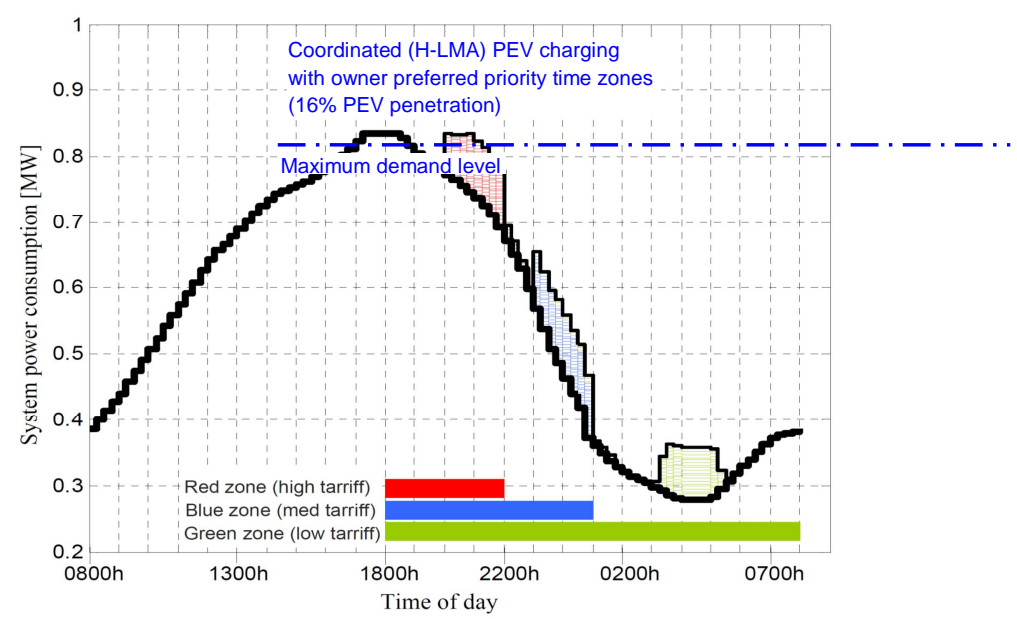

(c)

Fig. 5: System Power Consumption with Coordinated PEV Charging using the Proposed HLMA ( $\Delta t=15$ Min, $T=24$ Hours) for PEV Penetration Levels of; (A) 47\%, (B) 32\%, (C) $16 \%$.

\section{Conclusion}

This paper investigates the impacts of optimization parameters including optimization period $T$ and optimization time interval $\Delta t$ on the accuracy and the speed of a heuristic load management algorithm (H-LMA) that coordinates PEV charging activities while reducing system losses and regulating bus voltages over a 24 hour period. Main conclusions are:

- H-LMA will limit overall system overloads and voltage fluctuations while reducing stress on distribution circuits such as cables and transformers.
- The speed and accuracy of H-LMA depend on the selected values for $T$ and $\Delta t$.

- It is showed that optimization accuracy can be improved by using shorter time intervals and performing loss minimization over long periods (e.g,. 24 hours). This will however, require long computing times. Therefore, a compromise should be made between the solution accuracy and the associated computation time considering system size and the anticipated PEV penetration levels. 
- For online PEV coordination, small time interval and optimization period should be selected to start charging vehicles as quickly as possible; otherwise moderate time intervals with a large optimization period should be selected for offline coordination where all vehicles are plugged-in or their charging patterns are known/forecasted ahead of time.

\section{References}

Amin, S. M. (2008). "For the Good of the Grid," IEEE Power and Energy Magazine, 6 (6) 48-59.

Amin, S. M. \& Wollenberg, B. F. (2005). "Toward a Smart Grid: Power Delivery for the 21st Century," IEEE Power and Energy Magazine, 3 (5) 34-41.

Ashtari, A., Bibeau, E. \& Shahidinejad, M. (2012). "PEV Charging Profile Prediction and Analysis Based on Vehicle Usage Data," IEEE Transactions on Smart Grid, 3 (1) 341350.

Bashash, S. \& Fathy, H. K. (2012). "Transport-Based Load Modeling and Sliding Mode Control of Plug-In Hybrid Electric Vehicles for Robust Renewable Power Tracking," IEEE Transactions on Smart Grid, 3 (1) 526-534.

Clement-Nyns, K., Haesen, E. \& Driesen, J. (2010). "The Impact of Charging Plug-In Hybrid Electric Vehicles on a Residential Distribution Grid," IEEE Transactions on Power Systems, 25 (1) 371-380.

Deilami, S., Masoum, A. S., Moses, P. S. \& Masoum, M. A. S. (2011). "Real-Time Coordination of Plug-In Hybrid Electric Vehicles Charging in Smart Grids to Minimize Power Losses and Improve Voltage Profile," IEEE Transactions on Smart Grid, 2 (3) 456-467.

Han, S., Han, S. \& Sezaki, K. (2010). "Development of an Optimal Vehicle-ToGrid Aggregator for Frequency Regulation," IEEE Transactions on Smart Grid, 1 (1) 6572.
Khodayar, M. E., Wu, L. \& Shahidehpour, S. M. (2012). "Hourly Coordination of Electric Vehicle Operation and Volatile Wind Power Generation in SCUC," IEEE Transactions on Smart Grid, 3 (3) 1271-1279.

Lightner, E. M. \& Widergren, S. E. (2010). "An Orderly Transition to a Transformed Electricity System," IEEE Transactions on Smart Grid, 1 (1) 3-10.

Ma, Z., Callaway, D. S. \& Hiskens, I. A. (2013). "Decentralized Charging Control of Large Populations of Plug-In Electric Vehicles," IEEE Transactions on Control Systems Technology, 21 (1) 67-78.

Masoum, A. S., Abu-Siada, A. \& Islam, S. (2011). "Impact of Uncoordinated and Coordinated Charging of Plug-In Electric Vehicles on Substation Transformer in Smart Grid with Charging Stations," IEEE PES Innovative Smart Grid Technologies, Perth, Australia (2007) 1-7.

Masoum, A. S., Deilami, S., Moses, P. S. \& Masoum, M. A. S. (2011). "Smart Load Management of Plug-In Electric Vehicles in Distribution and Residential Networks with Charging Stations for Peak Shaving and Loss Minimisation Considering Voltage Regulation," IET Proceedings on Generation, Transmission and Distribution, 5 (8) 877888.

Moses, P. S., Deilami, S., Masoum, A. S. \& Masoum, M. A. S. (2010). "Power Quality of Smart Grids with Plug-In Electric Vehicles Considering Battery Charging Profile," IEEE PES Innovative Smart Grid Technologies, Gothenburg, Sweden (2010) 1-6.

Moses, P. S., Masoum, M. A. S. \& Hajforoosh, S. (2012). "Overloading of Distribution Transformers in Smart Grid Due to Uncoordinated Charging of Plug-In Electric Vehicles," IEEE PES Innovative Smart Grid Technologies, Gaithersburg, Maryland, USA (2012) 1-7.

Sortomme, E. \& El-Sharkawi, M. A. (2011). "Optimal Charging Strategies for Unidirectional Vehicle-To-Grid," IEEE Transactions on Smart Grid, 2 (1) 131-138. 
Wen, C. K., Chen, J. C., Teng, J. H. \& Ting, P. (2012). "Decentralized Plug-In Electric Vehicle Charging Selection Algorithm in Power Systems," IEEE Transactions on Smart Grid, 3 (3) 1179-1789.

Wu, D., Aliprantis, D. C. \& Ying, L. (2012). "Load Scheduling and Dispatch for Aggregators of Plug-in Electric Vehicles," IEEE Transactions on Smart Grid, 3 (1) 368376.

Zhao, J., Wen, F., Dong, Z. Y., Xue, Y. \& Wong, K. P. (2012). "Optimal Dispatch of Electric Vehicles and Wind Power Using Enhanced Particle Swarm Optimization," IEEE Transactions on Industrial Informatics, 8 (4) 889-899. 


\section{Appendix}

Parameters of the 19 bus low voltage and
31 bus distribution system are provided in Tables D1-D2 and Deilami et al (2011), respectively.

Table D1: Linear and Nonlinear (Pev) Loads of the Typical Low Voltage Residential System (Fig. 2)

\begin{tabular}{|l|l|c|c|}
\hline \multicolumn{2}{|c|}{ Linear and PEV Load } & \multicolumn{2}{c|}{ Power } \\
\hline Bus & Name & kW & kVAR \\
\hline 1 to 19 & $\begin{array}{l}\text { Linear } \\
\text { loads }\end{array}$ & 2.0 & 1.7 \\
\hline $\begin{array}{l}\text { Selected } \\
\text { buses }\end{array}$ & $\begin{array}{l}\text { PEV } \\
\text { charger }\end{array}$ & 4.0 & 0 \\
\hline
\end{tabular}

Table D2: Line Parameters of the Low Voltage Residential System (Fig. 2)

\begin{tabular}{|c|c|c|c|c|c|c|c|}
\hline \multicolumn{2}{|c|}{ LINE } & \multirow{2}{*}{$\begin{array}{c}\text { Line } \\
\text { resistance } \\
\mathrm{R}[\Omega]\end{array}$} & \multirow{2}{*}{$\begin{array}{c}\text { Line } \\
\text { reactance } \\
X[\Omega] \\
\end{array}$} & \multicolumn{2}{|c|}{ LINE } & \multirow{2}{*}{$\begin{array}{c}\text { Line } \\
\text { resistance } \\
\mathrm{R}[\Omega]\end{array}$} & \multirow{2}{*}{$\begin{array}{c}\text { Line } \\
\text { reactance } \\
X[\Omega] \\
\end{array}$} \\
\hline $\begin{array}{c}\text { From } \\
\text { bus }\end{array}$ & $\begin{array}{c}\text { To } \\
\text { bus }\end{array}$ & & & $\begin{array}{c}\text { From } \\
\text { bus }\end{array}$ & $\begin{array}{c}\text { To } \\
\text { bus }\end{array}$ & & \\
\hline $\mathrm{a}$ & $\mathrm{b}$ & 0.0415 & 0.0145 & $\mathrm{f}$ & 1 & 1.3605 & 0.1357 \\
\hline $\mathrm{b}$ & $\mathrm{C}$ & 0.0424 & 0.0189 & $\mathrm{~d}$ & $\mathrm{~m}$ & 0.140 & 0.0140 \\
\hline $\mathrm{C}$ & $\mathrm{d}$ & 0.0444 & 0.0198 & $\mathrm{C}$ & $\mathrm{n}$ & 0.7763 & 0.0774 \\
\hline $\mathrm{d}$ & $\mathrm{e}$ & 0.0369 & 0.0165 & $\mathrm{~b}$ & 0 & 0.5977 & 0.0596 \\
\hline $\mathrm{e}$ & $\mathrm{f}$ & 0.0520 & 0.0232 & $\mathrm{a}$ & $\mathrm{p}$ & 0.1423 & 0.0496 \\
\hline $\mathrm{f}$ & $\mathrm{g}$ & 0.0524 & 0.0234 & $\mathrm{p}$ & $q$ & 0.0837 & 0.0292 \\
\hline $\mathrm{g}$ & $\mathrm{h}$ & 0.0005 & 0.0002 & $q$ & $\mathrm{r}$ & 0.3123 & 0.0311 \\
\hline $\mathrm{g}$ & $\mathrm{i}$ & 0.2002 & 0.0199 & $\mathrm{a}$ & $\mathrm{s}$ & 0.0163 & 0.0062 \\
\hline $\mathrm{g}$ & $\mathrm{j}$ & 1.7340 & 0.1729 & \multirow{2}{*}{\multicolumn{3}{|c|}{$\begin{array}{l}\text { Distribution transformer } \\
\text { reactance }\end{array}$}} & \multirow{2}{*}{0.0654} \\
\hline $\mathrm{f}$ & $\mathrm{k}$ & 0.2607 & 0.0260 & & & & \\
\hline
\end{tabular}

Sara Deilami (S'09) received her B.S. and M.S. degrees in Electrical Engineering from Islamic Azad University, Tehran, Iran and Curtin University, WA, Australia in 2000 and 2011, respectively. She was awarded a Curtin University Postgraduate Scholarship (CUPS) and an Australian Postgraduate Award (APA) scholarship in 2010 and 2011, respectively. She is presently working towards a Ph.D. degree in Electrical Engineering at Curtin University, Perth, Australia. She has nine years of industry experience.

Amir S. Masoum (S'09) received the B.S. and M.S. degrees in electrical engineering and electrical utility engineering from the University of Western Australia, WA, Australia, and Curtin University, Perth, WA, Australia in 2009 and 2010, respectively. He is currently working toward the Ph.D. degree in electrical engineering at Curtin University, Australia. He has been a Project Manager at the Operational Asset
Management, Western Power, Kewdale, WA, since 2010. His research interests include optimization and control of smart grid, distributed generation, and renewable energy systems.

Mohammad A.S. Masoum (S'88-M'91SM'05) received his B.S., M.S. and Ph.D. degrees in Electrical and Computer Engineering in 1983, 1985, and 1991, respectively, from the University of Colorado, Boulder, USA. His research interests include optimization, power quality and stability of power systems and electric machines, as well as distributed generation. Dr. Masoum is the co-author of "Power Quality in Power Systems and Electrical Machines" (Elsevier, 2008) and "Power Conversion of Renewable Energy Systems" (Springer, 2011). Currently, he is a Professor and discipline leader for electrical power engineering at the Electrical and Computer Engineering 
Department, Curtin University, WA, Australia.

A. Abu-Siada (M'07, SM'12) received his B.Sc. and M.Sc. degrees from Ain Shams University, Egypt and the PhD degree from Curtin University, Australia, All in Electrical Engineering. Currently, he is a senior lecturer in the Department of Electrical and Computer Engineering at Curtin University. His research interests include power system stability, condition monitoring, power electronics and power quality. He is editor-in-chief for the electrical and electronic engineering international journal, a regular reviewer for many IEEE Transactions and a vice chair of the IEEE CIS, WA Chapter. 